\title{
Intramucosal Eosinophils Present
}

National Cancer Institute

\section{Source}

National Cancer Institute. Intramucosal Eosinophils Present. NCI Thesaurus. Code C82976.

A morphologic finding indicating the presence of eosinophils within the mucosa. 